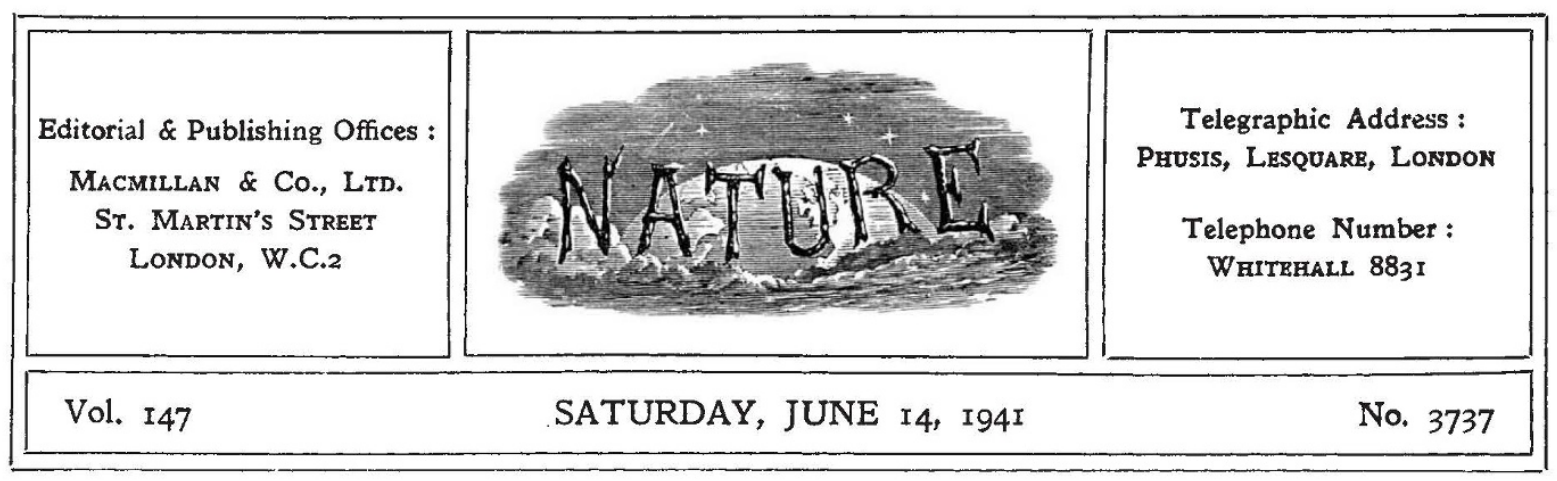

\title{
ORGANIZATION OF CIVIL DEFENCE
}

$\mathrm{T}$ HE Government decision to transfer the firefighting organizations from the control of local authorities, and to re-group and reinforce them under the general control of the Ministry of Home Security, thus establishing a national fire-fighting service, has been generally welcomed. The debates in the House of Commons indicate that the Reorganization of the Fire Services Act gives expression to a principle which is regarded as essential by all who have had first-hand experience of heavy air raids and which has already found firm advocacy in various reports and inquiries, from the P E P Broadsheet "London under Bombing" to the recent fourteenth report of the Select Committee on National Expenditure.

Inevitably the whole question of eivil defence administration is raised by a change of this magnitude, and the report of the Select Committee makes an important and opportune contribution to such discussion. The decision to base the administration of the fire services on the twelve Civil Defence Regions and as many sub-regions as efficiency requires involves important detailed reforms-the separation of the administrative from the executive side of fire-fighting, the appointment of recognized and recognizable chiefs to whom reinforcements can report on arrival in a heavily bombed area, and the strengthening of the firefighting army by the allocation to it of some of the men called up under the National Service Act. From such reforms it should be a simple matter to use regional authority to implement the main recommendations of the Select Committee in this field.

The more important of these recommendations are clearly matters in which regional authority can best help. A systematic attempt to ensure that all brigades should be given experience of fire-fighting under air-raid conditions ; the revision of the firefighting orders and the securing that fire-fighting parties are really efficient; the standardization of hours of duty of firemen and improvement of accommodation ; the development of the Supplementary Fire Party Service and its relation to the strength of the Auxiliary Fire Service, and measures to improve water supplies are all matters in which local authority or experience alone has been and is inadequate.

While it remains to be seen whether the Ministry of Home Security and the Regional Commissioners in different circumstances will receive the complete planning and the scale of equipment and personnel which will be adequate to bring sufficient forces to bear in time anywhere and everywhere the enemy may attack, it is significant that the Select Committee goes beyond the Government's present plans in contemplating no divorce between fire-fighting and fire-prevention. The trend of the report suggests that it is unlikely to countenance as adequate the immediate step of placing Miss Wilkinson, the efficient Additional Parliamentary Under-Secretary to the Ministry of Home Security, in charge of the training and equipment of the fire-fighting and fire-watching groups. It scarcely appears to give such parties the status, training and discipline of other Civil Defence Services as recommended in the Report, or to provide the nucleus of paid whole-time workers regarded as essential.

The importance of staff work in this field has not yet been fully appreciated, nor the two functions - that of the general staff officer and that of the officer in the line-clearly recognized. The chiefs of the various fire regions must be selected 
primarily for their administrative ability, while the Select Committee points to the necessity of also staffing key positions in constantly raided areas which involve continuous administrative duties with full-time workers chosen for such ability. Thorough training of the fire watchers and bringing this service to its full efficiency by the wise use of compulsory powers and establishment of close relations with the other fire services has an important bearing on the strength of the Auxiliary Fire Service.

While it is now recognized as beyond question that in any field of civil defence planning within the administrative boundaries of individual local authorities is disastrous to efficiency, the Select Committee does not consider that this alone is sufficient. Regional authority may be adequate to move unhesitatingly where required more than one third of a force from an area and to see that such reinforcements are adequately directed both en route and in action. Something more than regional authority is required, however, if the most efficient balance between whole-time and parttime personnel is to be secured.

Such matters as these involve the general question of man-power policy and the use of the powers of the Defence Regulations or relations with other Government Departments, and for these reasons the Report recommends further consideration of the concentration of all civil defence functions in a single Ministry. In particular the administration of all the civil defence functions of the Ministry of Health should be delegated to regional commissioners. Some of the shortcomings have been due to fundamental weaknesses in the administrative machine, such as lack of control by the central department. While the regional organization has avoided delay in reaching local decision, it has frequently failed to preserve control of policy. Its co-ordinating functions, particularly at the level of the central departments, through failure to see the problems of civil defence as a whole, have been seriously hampered by the division of responsibility between the Ministry of Home Security and the Ministry of Health or the Department of Health for Scotland, and the difference in the extent of departmental devolution for different services.

Co-ordination of the various Civil Defence Services and also economy, by avoiding duplication of inspectorial and administrative staffs, would be facilitated by the delegation to the Regional Commissioners of the administration of all the civil defence functions of the Ministry of Health and of the Department of Health for Scotland (with only such limitations as necessarily apply to the hospital services and evacuation). If, however, civil defence could be organized de novo it would undoubtedly be placed under a single Minister unburdened with other responsibilities, and the wisdom of this solution is well attested by the detailed recommendations of the Report, which so often reiterate proposals advanced elsewhere by Political and Economic Planning and other bodies. Moreover, strong support for the appointment of a single Minister of Civil Defence has been forthcoming from other quarters as indicated by press correspondence and articles.

There is, moreover, a further aspect of this question of Ministerial co-ordination which may be of importance in post-war developments of regionalism. Despite the impetus which the War has given to regionalism by revealing the weaknesses and limitations of local government, there does not appear to be any hostility on the part of the local authorities to regionalism. On the contrary, generally speaking, a happy co-operation has been established between the regional commissioners and the local authorities, and machinery at both ends has been improved and adjusted to meet constantly changing problems. Regional commissioners have rarely found it necessary to exercise their powers of superseding an inefficient local authority in its civil defence functions. Local authorities, however, were not designed to deal with the conduct of what the Home Secretary has described as a "military operation" on a large scale, and the closest co-operation between them can be no substitute for either regional or national control.

While, therefore, we may well hope that the stimulus to regionalism in civil defence or in other fields given by the War may prove invaluable in educating local authorities and public opinion as to the value of a regional approach to numerous other problems such as water or power supply, transport, land utilization, and the like after the War, it should not be forgotten that in a democracy regionalism is itself an instrument developed to meet particular conditions, and that it must satisfy the democratic conditions of flexibility and responsibility. It may well be necessary to extend the powers of the regional commissioners as part of the administrative machinery of military defence, for which local government cannot be expected to be suitable, and to make those powers more concrete 
in respect, for example, of food, evacuation and transport. If that is done, however, the question of public responsibility of the Commissioners becomes the more important under any democratic system.

To place the Commissioners under a single Ministry responsible to Parliament should go far to facilitate co-ordination and central control of policy and to meet the criticism of responsibility which has sometimes been advanced. Such a step might well ensure the fullest efficiency and dispel the uneasiness which may attach even in war-time to the entrusting of such wide powers to single individuals, in contrast to regional organizations, divorced from local responsibility in fields which have hitherto been administered largely from that point of view. We cannot afford even in war-time to overlook the importance for developing a democratic system, adequate to meet post. war demands, of continuously educating public opinion as to the issues involved and of digging the channels of assent to future changes or developments.

Apart from this broad question of administration, the Select Committee's report emphasizes the way in which the question of civil defence is linked up with the most efficient use of our man-power and woman-power. Its proposals for reducing the requirements of man-power for the Civil Defence Services are based on the experience which has now been gained of heavy raids, notably the outstanding fact that the loss of life and injury to persons has been much less than was expected, while material damage has been greater. Generally speaking, the Fire and Rescue Services have proved no more than adequate and in a few places actually deficient. Casualty services, on the other hand, have generally proved ample to meet the demands made upon them, and the Committee accordingly has been able to recommend reductions in the strength of these services.

Its main general recommendation for reducing the requirements of Civil Defence for man-power is the recruitment of part-time unpaid workers. Whole-time personnel should only be resorted to when part-time personnel cannot be obtained by voluntary recruitment or by compulsory enrol. ment under Defence Regulation 26A. In particular, the air-raid wardens' service should substantially revert to its original part-time basis and the paid element, so far as possible, be eliminated. Increase of the part-time element in the Report and Control Centres by encouraging the recruit- ment of business men and officials is also recommended, as well as consideration of the possibility of strengthening the Rescue Service by enlisting the building trades as a whole in an area for parttime service at normal rates of wages.

Other suggestions for saving man-power include the reduction of day-manning strengths to the minimum consistent with safety; the establishment of mobile reserves of rescue parties; the intensive review of operating methods and the review and reduction of the number of ambulances and first-aid posts in the light of present experience. Severe criticism is passed on the Fmergency Hospital Scheme for the absence of information which would enable any judgment to be reached as to whether nursing staffs are excessive, and the interchange of nursing staff between standing-by and hard-pressed hospitals is recommended.

Other severe criticism is passed on the shelter policy, the absence of standards, and the giving to the regional commissioners of a discretion amounting to control of policy. The amount of shelter, public and domestic, to be provided in less vulnerable areas should be clearly laid down according to a standard, and the places where shelter is to be provided should be determined on a definite classification of areas according to vulnerability. The administrative responsibility for the provision of all kinds of industrial shelter should be placed upon the regional commissioner and his technical staff.

These recommendations alone indicate how close and searching a scrutiny the Select Committee has made of the organization of civil defence, and how truly thinking minds have surveyed these problems. The Report indicates, indeed, that the right type of organization has been evolved, in the regional commissioners, to deal with the emergency problems which arise in heavy and sustained raids, calling for rapid, decisive directions. It is for our representative institutions to attest once more the swiftness of their capacity to respond to constructive criticism, to remedy proved weaknesses, and to strengthen and extend where required to such fields as food supply, housing, evacuation, transport and other services which may be required to deal with the social effects of severe attack, the co-operation and co-ordination which regional and central authority have been proved able to secure. Democracy must prove its fitness by its ability to learn from experience and its swiftness in applying that experience to meet changing needs. 